\title{
Distinguishing Features of Autism \\ in Boys with Fragile X Syndrome
}

\section{Matt Brock}

A thesis submitted to the faculty of the University of North Carolina at Chapel Hill in partial fulfillment of the requirements for the degree of Master of Arts in the School of Education (Early Childhood, Intervention and Literacy).

\section{Chapel Hill}

2009

Approved by:

Harriet Boone

Deborah Hatton

Samuel Odom 


\begin{abstract}
Matt Brock: Distinguishing Features of Autism in Boys with Fragile X Syndrome
\end{abstract} (Under the direction of Deborah Hatton)

Children with fragile X syndrome (FXS) have a much higher prevalence of autism than typical children in the general population. Children with comorbid FXS and autism represent a distinct subgroup of children with FXS that is at risk for markedly poorer outcomes. Evidence shows that early identification and intervention can improve outcomes. To further efforts to create a specialized autism screener for young males with FXS that could assist in early identification, this study explores the association of selected parent-report questionnaire items with autism symptoms in a sample of 60 boys with FXS, ages 4-18 years old. Findings demonstrate that both social and repetitive behaviors distinguish children with comorbid FXS and autism from children with only FXS, with repetitive behaviors playing a much more prominent role than previously documented in the literature. The results of this study provide evidence that a well designed parent-report questionnaire that focuses on specific distinguishing behaviors might serve as an effective tool for early identification of autism in the FXS population. 


\section{Table of Contents}

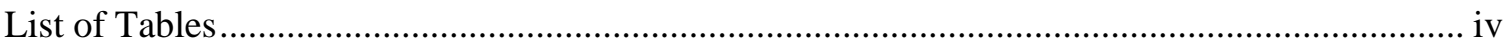

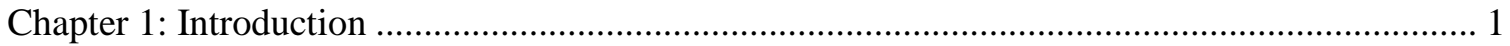

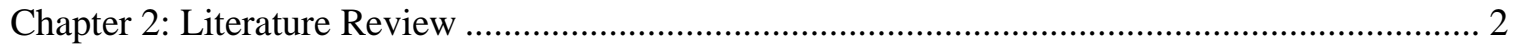

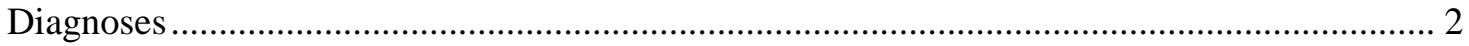

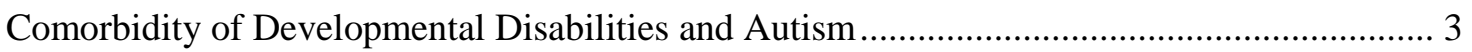

Improving Outcomes for Children with Both FXS and Autism ............................................. 4

Identification of Autism in Young Children with FXS ....................................................... 5

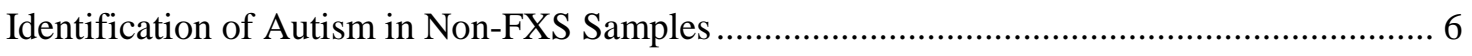

Selecting Screening Items: Features Unique to Children with Comorbid FXS ....................... 8

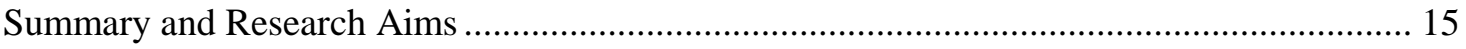

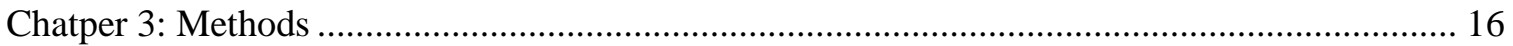

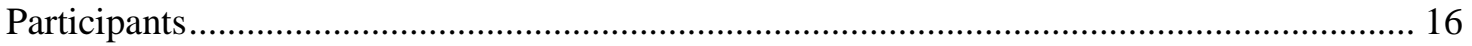

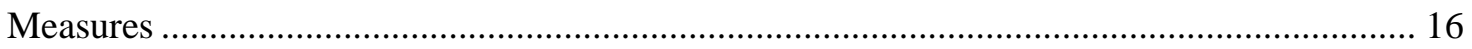

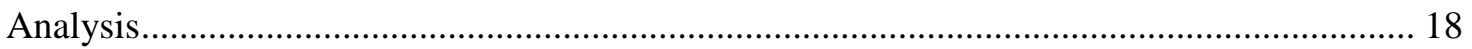

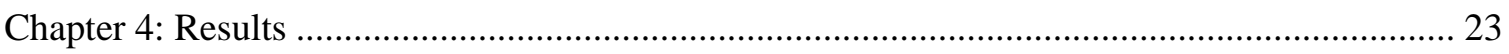

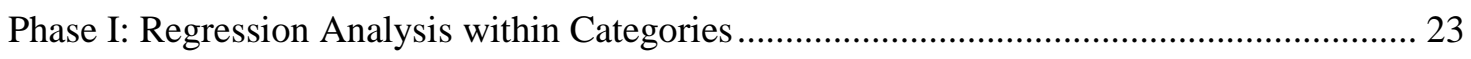

Phase II: Regression Analysis among Categories ................................................................ 25

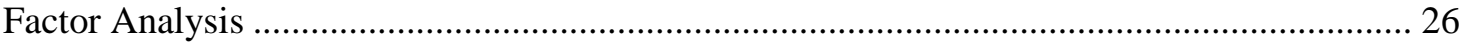

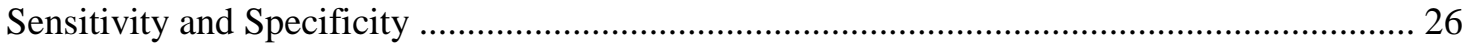

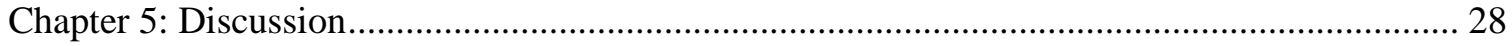

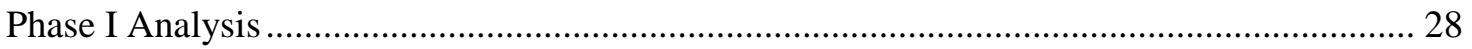

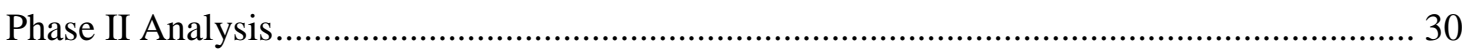

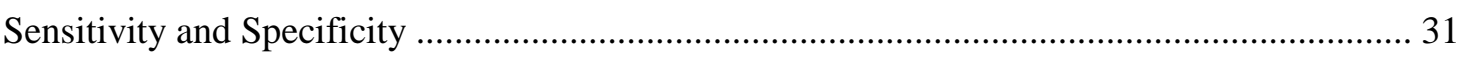

Limitations and Directions for Future Research ............................................................... 32

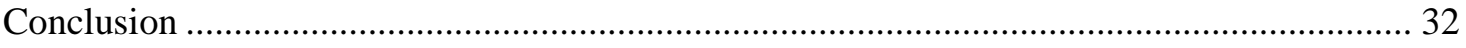

Appendix A: Intercorrelations Between Items Within Categories ............................................... 33

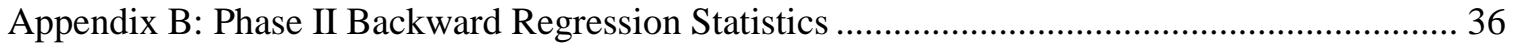

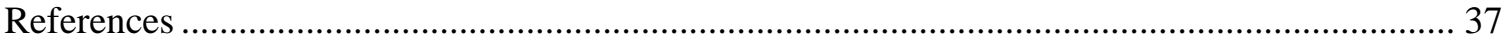




\section{List of Tables}

Table 1: Items that Relate to Social Anxiety, Withdrawal, and Avoidance.....................20

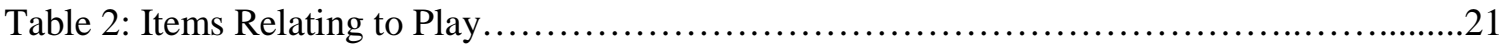

Table 3: Items Relating to Adaptive Socialization..........................................22

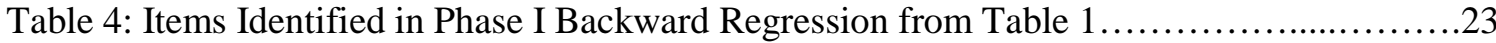

Table 5: Items Identified in Phase I Backward Regression from Table 2.....................24

Table 6: Items Identified in Phase I Backward Regression from Table 3 ......................25

Table 7: Items Identified in Phase II Backward Regression Analysis.........................25

Table 8: Intercorrelations Between Items Identified in Phase II Analysis......................26

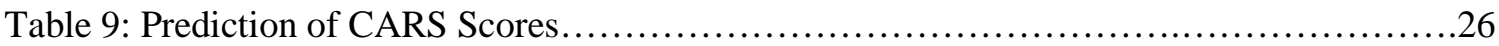

Table 10: Sensitivity and Specificity of Summed Score of Identified Items......................27

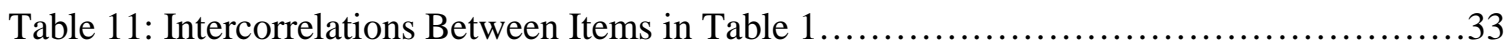

Table 12: Intercorrelations Between Items in Table 2 ..................................... 34

Table 13: Intercorrelations Between Items in Table 3................................... 35

Table 14: Phase II Backward Regression Statistics......................................... 36 


\section{Chapter 1: Introduction}

Children with fragile X syndrome (FXS) are at higher risk for autism compared to typically developing children in the general population (Clifford et al., 2007; Demark et al., 2003; Hagerman et al., 2006; Hatton et al., 2006; Lewis et al., 2006; Rogers et al., 2001) and children with other developmental disabilities (Collacott, Cooper, \& McGrother, 1992; Kent, Evans, Paul, \& Sharp, 1999). Children with comorbid FXS and autism are likely to have poorer outcomes than children with only FXS or only autism (Bailey et al., 2000; Bailey et al., 2001; Hatton et al., 2002; Hatton et al., 2006; Kau et al., 2004; Lewis et al., 2006; Rogers et al., 2001). Because research demonstrates that early intervention techniques improve outcomes for young children with autism (National Research Council, 2001), it is imperative that young children with comorbid FXS and autism be identified as early as possible.

Based on a literature review describing specific behavioral features that may distinguish children with comorbid FXS and autism from children with only FXS, specific items from behavioral questionnaires were selected. Then regression analysis was used to identify which questionnaire items were the most predictive of autism status in a sample of children with FXS. Findings from this analysis provide insight into how to best identify young males with FXS who have autism. 


\section{Chapter 2: Literature Review \\ Fragile $X$ and Autism}

\section{Diagnoses}

Diagnosing fragile $x$ syndrome. Fragile $\mathrm{X}$ syndrome, the most common inheritable genetic cause of intellectual disability, affects approximately 1 in 2,500 males and 1 in 8,000 females (Crawford, 2001). Fragile X syndrome (FXS) is caused by an underlying genetic disorder at Xq27.3 on the $\mathrm{X}$ chromosome, also called the fragile $\mathrm{X}$ mental retardation gene, or FMR1. While the general population has between 6 and 55 repeats of a CGG trinucleotide on this gene, persons with full mutation FXS have over 200 repeats. This high number of repetitions impairs the gene's ability to code for the fragile X mental retardation protein (FMRP). This protein plays an important role in brain and tissue development, and its absence in children with FXS leads to significantly impaired outcomes. Physical characteristics in males may include intellectual disability, unusually high foreheads, unbalanced faces, large jaws, long protruding ears, and large testicles after puberty. Males, having only one X chromosome, are more frequently affected by FXS and tend to have more severe impairments (Crawford). Females are able to code for FMRP with a second $\mathrm{X}$ chromosome, typically resulting in milder impairments than seen in males. Common symptoms in females with FXS include social anxiety, mild cognitive impairments, and learning disabilities (Hagerman et al., 1992; Hatton et al., 2009). Because of its known genetic underpinnings, FXS can be detected through blood testing, or prenatally through chorionic villus sampling or amniocentesis (Crawford).

Diagnosing autism. Unlike FXS, which has a known single genetic cause, a definitive genetic marker for autism has not been identified. In fact, developments in current research 
suggest that autism most likely does not have a single genetic basis (Happe, Ronald, \& Plomin, 2006). Without a known etiology, autism is defined behaviorally by impairments in social interaction and communication, and by restricted interests and/or repetitive behaviors. While a single cause of autism is unlikely to be discovered, specific neural risk factors have been identified. For example, the presence of autism has been found to be associated with abnormal levels of specific neurotransmitters (Belmonte \& Bourgeron, 2006).

\section{Comorbidity of Developmental Disabilities and Autism}

One type of these neurotransmitters, metabotropic glutamate receptors, is normally regulated by FMRP. In FXS, diminished levels of FMRP impede normal interaction with these receptors, resulting in abnormal development of dendritic spines. This interaction suggests that FXS is a neural risk factor for autism (Belmonte \& Bourgeron, 2006; Catania et al., 2007). This link is supported by studies that document an association between autistic behaviors and levels of FMRP in individuals with FXS (Hatton et al., 2006; Loecsh et al., 2007). The connection between the two disorders is also strongly supported by a high prevalence of autism within the FXS population. Reported rates of prevalence of autism in males with FXS range from 18-47\%, depending on the diagnostic tool and sample size (Clifford et al., 2007; Demark et al., 2003; Hagerman et al., 2006; Hatton et al., 2006; Lewis et al., 2006; Rogers et al., 2001). When the category is broadened to include both autism and autism spectrum disorders, the prevalence for males with FXS has been reported as high as $67 \%$ (Clifford et al.).

Ninety percent of males with FXS display at least one behavior that is characteristic of autism (Hagerman, 2002), suggesting that most boys with FXS, even those who do not meet criteria for autism, display some autistic behaviors such as gaze aversion (Cohen et al., 1989). As a group, boys with FXS have significantly more echolalia, repetitive speech, and hand flapping than boys with idiopathic intellectual disabilities or Down syndrome (Turk \& Graham, 1997). 
Some researchers have even suggested that FXS should be categorized as a subtype of autism (Gillberg, Persson \& Wahlstrom, 1986).

Other developmental disabilities do not have such high rates of comorbidity with autism. For instance, only an estimated 2-7\% of children with Down syndrome have autism spectrum disorders (Collacott et al., 1992; Kent et al., 1999). In fact, the group profile of children with Down syndrome is markedly different from that of children with autism. Children with Down syndrome tend to have relative strengths in initiating joint attention, social motivation, and imaginary play (Sigman et al., 1999), areas of relative weakness for children with autism. Low comorbidity with autism is not unique to Down syndrome. In a comparison group of children with heterogeneous developmental disabilities other than Down syndrome, only $4.3 \%$ had autism spectrum disorders (Collacott et al.). FXS is not the only syndrome that puts children at increased risk for being diagnosed with autism; there are also a few rare genetic disorders that are suspected risk factors for autism. However, none of these syndromes is more common than FXS, and more children with autism spectrum disorders have FXS than any other autism related syndrome (Abrahams \& Geschwind, 2008). FXS accounts for 2-3\% of all children with autism (Abrahams \& Geschwind; Bailey, Phillips, \& Rutter, 1996).

\section{Improving Outcomes for Children with Comorbid FXS and Autism}

Although most children with FXS display some level of autistic behavior (Hagerman, 2002), evidence suggests that those who meet diagnostic criteria for autism represent a distinct subgroup that is at risk for markedly poorer outcomes (Bailey et al., 2000; Bailey et al., 2001; Hatton et al., 2002; Hatton et al., 2006; Kau et al., 2004; Lewis et al., 2006; Rogers et al., 2001). When compared to groups of children with only FXS or autism, children with both FXS and autism had poorer social and communication skills and greater cognitive impairment (Bailey et al., 2000). Children with comorbid FXS and autism also have significantly lower adaptive behavior scores (Bailey et al., 2001; Kau et al.) and significantly more problem behaviors (Hatton 
et al., 2002) than children with FXS alone. In sum, children with comorbid FXS and autism consistently score lower on developmental measures than children with only FXS or autism, and display a unique profile distinct from children with only FXS or other developmental disabilities (Rogers et al., 2001).

So what can be done to improve the outcomes of children who have comorbid FXS and autism? There is consensus that early identification and intervention lead to improved outcomes for children with autism (National Research Council, 2001). Even though FXS is a known risk factor for autism, there is no simple screening instrument specific to FXS that can be used to efficiently aid in the early identification process. The imperative for screening all young children with FXS for autism is clear, but the problem is developing a sensitive and accurate screener for this population.

\section{Identification of Autism in Young Children with FXS}

Unfortunately, differentiating young children with FXS who will later be diagnosed with autism from those who will not be diagnosed with autism can be problematic. Because $90 \%$ of children with FXS display at least one autistic behavior (Hagerman, 2002), and 67\% eventually meet criteria for an autistic spectrum disorder (Clifford et al., 2007), those who will later display the most severe autistic behavior and meet criteria for autism disorder may not appear significantly different from other children with FXS at a young age. This was demonstrated when Baranek and her colleagues (2005) examined retrospective videotape footage of infants with FXS between 9 and 12 months old who were later diagnosed with autism. They found that these infants more closely resembled infants with developmental delays than infants with idiopathic autism.

However, there is evidence that a screener could be effective for children as young as 21 months old (Rogers et al., 2001). Rogers and colleagues studied slightly older children, ages 21- 
48 months, and found that children with comorbid FXS and autism could be differentiated from children with only FXS based on adaptive and developmental measures.

To date, only one published study has used an autism screener with a group of children with FXS (Scambler, Hepburn, Hagerman, \& Rogers, 2007). In this study, the Checklist for Autism in Toddlers (CHAT; Baron-Cohen, Allen, \& Gillberg, 1993) was used. The CHAT, composed of 14 yes or no questions, is intended to be used by general practitioners to screen for autism during 18-month developmental check-ups. The first nine items are answered by the parent, while the other five are answered by the doctor or health worker through observation (Baron-Cohen et al.). When used as a screener with children with FXS, the CHAT only correctly flagged 50\% of children who met DSM-IV autism criteria (Scambler et al.). Although sensitivity was poor, the CHAT was highly specific (100\%). Adding additional special criteria (the Denver Criteria) to the screener did increase the number of children correctly flagged, but also equally increased the number of children incorrectly flagged (Scambler et al.). It should be noted that Scambler and his colleagues used a relatively small sample of children with FXS $(N=17)$, so generalization of their findings may be limited. However, if studies of autistic children without FXS are any indication, 50\% sensitivity may actually be an inflated estimate. When the CHAT was initially developed for young children with idiopathic autism, a similarly high level of specificity (98\%) and an even lower level of sensitivity (38\%) were reported (Baron-Cohen et al.). While these levels of specificity and sensitivity may be useful for detecting children at risk for autism in the general population, the CHAT does not provide an adequate level of sensitivity for screening children who already have a known risk factor for autism, such as FXS.

\section{Identification of Autism in Non-FXS Samples}

While no other research groups appear to have investigated autism screeners with a sample of children with FXS, some commonly used autism screeners have been tested with similar populations. For instance, the Social Communication Questionnaire (SCQ) and the Social 
Responsiveness Scale (SRS) have been used with subgroups of children with low cognitive functioning and high levels of problem behavior (Charman et al., 2007). Low cognitive functioning (Bailey et al., 2001) and high levels of problem behavior (Hatton et al., 2002) are common in the FXS population, and how these characteristics affect the efficacy of screeners is relevant to how the screeners might perform with children who have FXS. Both the SCQ (Rutter, Bailey, \& Lord, 2003) and SRS (Constantino \& Gruber, 2005) are parent-report questionnaires. The SCQ (Rutter et al.) is composed of 40 items to which the parent responds yes or no, and one of its intended uses is to approximate the severity of autism spectrum disorder symptomology. The SRS (Constantino \& Gruber) is composed of 60 items on a five-point Likert scale, and one of its intended uses is to aid in the clinical diagnoses of autism disorder, Aspergers, PDD-NOS, and schizoid personality disorder of childhood. Both screeners suggest cut-off scores for flagging children for formal autism testing.

In a validation study, both the SCQ and the SRS performed impressively in a sample of 119 children ages 9-13 with special educational needs (Charman et al., 2007). The SCQ was highly sensitive (86\%) and specific (78\%) in correctly flagging children who had been diagnosed with autism spectrum disorders. The SRS performed similarly well, with $78 \%$ sensitivity and $67 \%$ specificity. However, when screening subgroups of children with low cognitive functioning, the SCQ was markedly less sensitive (73\%) and in a subgroup of children with high levels of behavior problems, the SRS was markedly less specific (41\%; Charman et al.). These findings suggest that screeners that perform well in heterogeneous samples may sacrifice either sensitivity or specificity in samples characterized by low cognitive functioning and high levels of problem behavior, two common traits in the FXS population (Bailey et al., 2001; Hatton et al., 2002).

In sum, there is a body of evidence demonstrating that children with comorbid FXS and autism are at risk for markedly poorer outcomes than children with FXS alone, and there is reason to believe that early identification and intervention would improve these outcomes. However, 
accurately screening children with FXS at an early age for autism remains a challenge, as current screening tools may not be optimal. To better identify young children with FXS who will be later diagnosed with autism, the specific behaviors and risk factors that differentiate this group must be closely examined. These behaviors fall primarily into one of three broad categories:

communication, social behavior, and problem/aberrant behaviors. The evidence supporting each of these categories will be explored.

\section{Selecting Screening Items: Features Unique to Children with Comorbid FXS}

A systematic review of the literature was conducted to explore each category of behavior. The selection of literature was guided by several criteria. First, only quantitative studies with samples of fifteen or more young children with FXS were selected. However, the most frequently cited studies included considerably larger sample sizes; many had sample sizes larger than 50, and several studies included more than 100 participants. Also, while care was taken to select studies with younger participants (ages 2-5), several of the studies included broader age groups. Second, the studies had to directly compare a group of children with FXS with autism disorder or autism spectrum disorders with a group of children with FXS who did not meet diagnostic criteria for autism. Most studies also included other groups of children for comparison, including groups characterized by idiopathic autism, developmental delays, or typical development. Third, studies had to demonstrate significant differences between groups using accepted statistical methods. And finally, because the aim of this review was to synthesize the most recent evidence, only studies published after the year 2000 were included. Because males significantly outnumber females with FXS, are typically more severely impaired by FXS, have a higher rate of FXS and autism comorbidity, and are more often the subjects of FXS studies, the reviewed literature deals almost exclusively with young boys. Most of the studies reviewed compared individuals with FXS with and without autistic disorder, although some use the broader classification of autism spectrum disorder (Budimirovic et al., 2007), and others have one subgroup with autism disorders 
and another with autism spectrum disorders (Kaufmann et al., 2004). However, in some cases this distinction is not relevant, as a number of the findings resulted from analyses using associated features to predict continuous scores on autism diagnostic tools (such as ADI-R or CARS total scores) rather than to predict group membership. When studies are discussed that involve prediction of group membership, studies that used the broader classification of autism spectrum disorder (ASD) are explicitly noted.

\section{Communication}

Several research groups have explored how impaired communication, a key criterion for autism diagnosis, may relate to autism in FXS (Lewis et al., 2006; Loesch et al., 2007; Philofsky et al., 2004; Price, Roberts, Vandergrift, \& Martin, 2007; Roberts, Mirrett, \& Birchinal, 2001). Several researchers found that children with comorbid FXS and autism have a language profile distinct from other children with FXS. Philofsky et al. found that although young children with FXS (ages 2-5) have significantly impaired communication as measured by the Mullen Scales of Early Learning (Mullen, 1995), receptive language was a relative strength when compared to expressive language. Children with both FXS and autism, however, had lower overall communication skills, and receptive language skills were similar to expressive language skills, resulting in a flat language profile. Lewis and colleagues corroborated significant differences in receptive language between those who do and do not have autism, even after controlling for level of cognitive functioning. However, other researchers using the same or similar measures of receptive language did not find significant differences in receptive language skills (Price et al., 2007; Roberts et al.).

Two research groups (Kaufmann et al., 2004; Loesch et al., 2007) administered a variety of test batteries to children with FXS, then analyzed communication subscale scores for correlations with the two most highly regarded autism diagnostic tools, the Autism Diagnostic Observation Schedule-Generic (ADOS-G; Lord et al., 2000) and Autism Diagnostic Interview- 
Revised (ADI-R; Lord, Rutter \&, Le Couteur, 1994). Loesch and colleagues found that the Controlled Oral Word Association Test (COWAT), a measure of verbal fluency, was a significant predictor of ADOS-G scores. However, other research groups did not find significant differences in expressive language (Lewis et al., 2006, Philofsky et al., 2004). Kaufmann and colleagues found that the adaptive communication subscale of the Vineland Adaptive Behavior Scales, when covaried with the adaptive socialization subscale, predicted ADI-R scores. However, when the adaptive communication and socialization subscales were analyzed as separate variables, only the socialization subscale was a significant predictor of autism.

There are not any factors relating to communication that are consistently predictive of autism status in males with FXS across studies. Even if significant differences found in individual studies were not contradicted elsewhere in the literature, most represent broad findings detected only after administering entire diagnostic batteries; closer examination of subscales and individual items did not reveal any specific features that were strongly predictive of autism. As Kaufmann and his colleagues (2004) suggest, perhaps social behavior, rather than communication, is the domain that best discriminates between children with FXS who do and do not have autism.

\section{Social behavior}

A number of researchers suggest that social behavior may predict autism status in males with FXS (Budimirovic et al., 2006; Kau et al., 2004; Kaufman et al., 2004; Roberts, Weisenfeld, Hatton, \& Heath, 2001). Budimirovic and his colleagues examined how well specific social items from rating scales predicted ASD status in young boys, 3-8 years old, with FXS. They found that adaptive socialization and social withdrawal were independent predictors of ASD in FXS, with adaptive socialization being the stronger predictor. As a composite, the social subscales from the Vineland Adaptive Behavior Scale (VABS) and the Aberrant Behavior Checklist (ABC; Aman, Stewart, \& Field, 1985) were highly sensitive and specific predictors of autism. Seventy-seven 
percent of subjects were correctly classified as having ASD, while $90 \%$ of those without ASD were also correctly classified. The VABS social subscale was significantly correlated with ASD classification, replicating a finding in an earlier study by Kaufmann and colleagues. Within the VABS subscale, six specific items were tested as informative items. As a composite, these items were highly predictive of ASD status (they correctly classified $87 \%$ of subjects with ASD, and $82 \%$ without) and three of the individual items were each independently significantly related to ASD status. These three items included item 24 (label happiness, sadness, fear and anger in oneself), item 31 (respond verbally and positively to good fortune in others), and item 38 (respond appropriately when introduced to others).

Social avoidance was not found to be as strong of a predictor as adaptive socialization, and its correlation with ASD status was only significant with older subjects (Budimirovic et al., 2006). When applied to a subgroup of subjects five years old or older, a group of five informative items from the Aberrant Behavior Checklist (ABC) was highly predictive of ASD status (correctly classifying $75 \%$ of subjects with ASD, and $93 \%$ without). Only one individual item had a statistically significant association with ASD status: item 42 (withdrawn, prefers solitary activity, socially isolative). The authors conclude that unlike children with idiopathic autism, "true social avoidance, but not social indifference, appears to be linked to ASD in FXS particularly in older boys" (Budimirovic et al., p. 1823).

This distinction supports the argument made by Roberts et al. (2007) that children with FXS have high levels of social anxiety, and that those who also have autism can be distinguished by their inability to modulate their social behavior over time. The authors of this study theorize that most children with FXS are socially anxious and withdraw in novel situations, but that their social interactions improve in more familiar contexts. Children with FXS and autism, however, display social withdrawal regardless of whether the situation is novel or familiar. This idea is supported by the study's reported observations using the Social Approach Scale (SAS), which 
includes measurements of physical movement, facial expression, and eye contact. SAS scores taken at the beginning and end of observation days indicated that for children with only FXS, social approach improved as they spent more time with the examiner. Children with FXS and autism, however, showed poorer initial approach and less improvement with exposure to the examiner. The SAS scores were correlated with Childhood Autism Rating Scale scores (CARS; Schopler, Reichler, DeVellis, \& Daly, 1980), and physical movement, facial expression, and eye contact were all statistically significant predictors of autistic behavior. Of these predictors, modulated eye contact was the best predictor of autism status. The lack of increase in eye contact after spending time with an examiner most clearly distinguished boys with FXS and autism from children with FXS alone (Roberts et al.). Much like the aforementioned study (Budimirovic et al., 2006), differences in social avoidance in boys with FXS and autism were more pronounced in older boys (Roberts et al.). This mirrors a similar finding that CARS scores for children with FXS may increase slightly with age (Hatton et al., 2006), rebutting previous theories that young children with FXS are more likely to exhibit autistic behavior than older children with FXS.

Kaufman and his colleagues (2004) also found that young children with FXS and autism showed significant social deficits. In fact, social interaction scores fell onto a continuum that corresponded with autism disorder and autism spectrum disorder diagnoses. Children with FXS alone showed the mildest social deficits, while children who also had ASD showed moderate deficits, and children with FXS and autism disorder displayed the most severe deficits. There were significant differences between social interaction scores for children with FXS and ASD from children with only FXS. When ADI-R (Autism Diagnostic Interview-Revised) items were analyzed to find which specific test items were most predictive of autism diagnosis, items reflecting imaginative play and peer interaction emerged (Kaufman et al.). 


\section{Problem/aberrant behavior}

Poorer communication and social skills in children with autism are often related to increased levels of behavior problems (Mancil, Conroy, Nakao, \& Alter, 2006). Therefore, although differences in problem behavior make a unique contribution to distinguishing autism in FXS, it is not surprising that there may be some overlap with previously discussed social and communication factors.

Total problem behavior scores from the Child Behavior Checklist (CBCL; Achenbach \& Rescorla, 2001) have been found to be significantly correlated with autistic behavior in children with FXS, and stable over a three year period for boys 4-12 years old (Hatton et al., 2002). Other researchers concur that children with FXS and autism have higher CBCL total problem behavior scores than children with FXS alone (Kau et al., 2004). While total problem behavior scores are related to autistic behavior, the most useful information from the CBCL may come from inspection of individual subscales and test items within these scores. Overall scores are unlikely to distinguish children who have autism from other children with FXS, as about half of children with FXS score within the borderline or clinical range for total problem behavior (Hatton et al., 2002; Hessl et al., 2001).

Closer examination of CBCL scores revealed significant differences in internalizing, but not externalizing, behaviors (Kau et al., 2004). Specifically, children with comorbid FXS and autism had significantly higher scores for 'withdrawn' (Budimirovic et al., 2006; Kau et al.; Kaufman et al., 2004) and 'attention problem' (Kau et al.) subscales. Hatton and colleagues (2002) did not find significant differences for attention, but suggest that the stimulant medications being prescribed to a large number of their subjects may have masked a possible effect. When the 'withdrawn' subscale was analyzed, it was found that a disproportionate number of items related to social avoidance behaviors (Budimirovic et al.). These include item 75 (shy or timid), item 88 (sulks a lot), item 111 (withdrawn, does not get involved with others), item 42 (would rather be 
alone than with others), and item 65 (refuses to talk). Although boys with FXS and autism scored higher on the withdrawn subscale than children with idiopathic autism, their CBCL total scores were otherwise comparable to children with idiopathic autism (Kau et al.).

The Aberrant Behavior Checklist-Community (ABC-C) has also been used to probe for differences in individuals with FXS with and without autism. Significant differences have been found for the stereotypic behaviors subscale (Kau et al., 2004) and lethargy/social withdrawal subscale (Budimirovic et al., 2006; Kau et al.). The only individual ABC-C item significantly correlated with autism diagnosis was item 42 (withdrawn, prefer solitary activity, socially isolative). Although the total ABC-C and CBCL scores were similarly predictive of autism (the CBCL had slightly improved sensitivity while the ABC-C had better specificity), the ABC-C lethargy/social withdrawal subscale was more predictive of autism in FXS than the CBCL withdrawn subscale (Budimirovic et al.).

It should be noted that problem behaviors in children with FXS have been correlated with environmental factors. Hessl and colleagues (2001) found that CBCL total scores were correlated with the quality of education and therapy services as reported by parents. They found that these environmental quality scores, not IQ or FMRP level, were the best predictor of problem behaviors. In view of this finding, perhaps problem behaviors alone may not be the best predictor of autism in FXS, as they may reflect environmental differences.

Other behaviors

While some studies did not meet the criteria for this literature review, they do identify findings that may be related to autism status in the FXS population. For example, although Baranek and colleagues (2005) did not compare subgroups of children with FXS with and without autism, their comparison of very young children with FXS, idiopathic autism, and other developmental disabilities yielded some unique distinguishing features. Using retrospective video analysis, they found that children 9-12 months old with FXS were best distinguished from 
children with other developmental disabilities by unusual object play (including spinning objects) and unusual motor patterns (including repetitive leg movements). Because these features relate to repetitive behaviors and restricted interests, a defining category of autistic behavior, it is possible that they might distinguish children with comorbid FXS and autism from children with only FXS.

\section{Summary and Research Aims}

If educational services for children with FXS and autism are to be improved, early identification and intervention are paramount. Current autism screeners for young children are not sensitive enough to identify the majority of children with FXS who will later be diagnosed with autism (Scambler et al., 2007) and a more specialized screener for the FXS population is needed. A review of the literature demonstrates that a number of research groups have identified specific behavioral traits that distinguish children with comorbid FXS and autism from children with FXS alone. The present study aims to explore how well questionnaire items related to these distinguishing traits predict overall autism symptom severity in children with FXS.

Based on the most promising findings in the literature that identify specific behaviors that may distinguish children with comorbid FXS and autism from other children with FXS, three major categories of behavior were identified. These categories include (a) social anxiety, withdrawal, and avoidance (Budimirovic et al., 2006; Kau et al., 2004; Kaufman et al, 2004; Roberts et al., 2001); (b) play, specifically imagination, peer interaction, and object play (Baranek et al., 2005; Kaufman et al., 2004); and (c) adaptive socialization, specifically recognizing emotions in self and others (Budimirovic et al., 2006; Kau et al., 2004; Kaufmann, 2004).

The present study tests the hypothesis that questionnaire items related to each of these three respective categories will predict autistic behavior in children with FXS. Furthermore, an optimal combination of items from these categories will be identified. The ability of this combination of items to predict autistic behavior in children with FXS will be directly compared to the performance of two traditional autism screeners with a sample of boys who have FXS. 


\section{Chapter 3: Methods}

\section{Participants}

The participants for this study were a subgroup of subjects from the Carolina Fragile X Project who recently participated in a pilot study of the genetics of ASD in males with FXS, for which informed consent had been obtained. De-identified data were used for this study. Participants included 60 boys with full mutation FXS who were between 4 and 18 years old $(M=$ 11.9; $S D=4.4)$. To be included in this study, three behavioral measures must have been collected for participants, including the Social Responsiveness Scale (SRS; Constantino \& Gruber, 2005), the Social Communication Questionnaire (SCQ; Rutter, Bailey, \& Lord, 2003), and the Repetitive Behavior Scale (RBS; Bodfish, Symons, \& Lewis, 1999). In addition, scores from the Childhood Autism Rating Scale (CARS; Schopler, Reichler, DeVellis, \& Daly, 1988) were used to describe autism symptom severity.

\section{Measures}

The SRS (Constantino \& Gruber, 2005) is a 65-item parent-report questionnaire designed to be used as a screener for autism, Aspergers, PDD-NOS, and schizoid personality disorder of childhood. Items are answered on a five-point Likert scale and summed to yield five subscale scores (social awareness, social cognition, social communication, social motivation, and autistic mannerisms) and a total score. The scoring algorithm for the SRS involves reverse scoring some items so that higher scores represent greater autism symptom severity. When referenced in the analysis, items that have been reverse scored are underlined. For a child in a clinical or educational setting already suspected of having social development problems, a total score of 85 
or greater suggests that the child may have an autism spectrum disorder and that further evaluation is warranted (Constantino \& Gruber).

The SCQ (Rutter et al., 2003) is a 40-item parent-report questionnaire designed to provide a dimensional measure of autism symptomology, compare overall levels of autism symptomology across samples, and to approximate severity of autism symptomology. Parents respond yes or no to each item, and items are summed to yield three subscale scores (reciprocal social interaction; communication; and restricted, repetitive, and stereotyped patterns of behavior) and a total score. The scoring algorithm for the SCQ involves reverse scoring some items so that higher scores represent greater autism symptom severity. When referenced in the analysis, items that have been reverse scored are underlined. A total score of 15 or greater suggests that a formal autism evaluation may be warranted. The SCQ was designed as a companion screener for the Autism Diagnostic Inventory-Revised (ADI-R; Lord, Rutter, \& Le Couteur, 1994) and SCQ subscale scores match and agree well with ADI-R domain scores (Rutter et al.).

The RBS (Bodfish, Symons, \& Lewis, 1999) is designed to assess the presence and severity of abnormal repetitive behaviors and restricted interests associated with disorders such as autism spectrum disorders and mental retardation. Items are rated on a five-point Likert scale and summed to yield five subscale scores (stereotypic behavior, self injurious behavior, compulsive behavior, ritualistic/sameness behavior, and restricted interests) and a total score using a revised scoring algorithm. The RBS is an experimental instrument, and its psychometric properties have been assessed in an independent validation study (Lam \& Aman, 2007).

The CARS (Schopler, Reichler, DeVellis, \& Daly, 1988) is a 15-item rating system on which professionals rate items on a scale from 1 (within normal limits) to 4 (severely abnormal). The total score from the CARS represents a measure of autism symptom severity. Individuals scoring 30 or above are considered autistic, while those scoring 37 and above are considered severely autistic (Schopler, Reichler, DeVellis, \& Daly). One of the advantages of the CARS is 
that it yields a single score that is a continuous measure of autistic behavior (Bailey et al., 2001; Hatton et al., 2009). Multiple research groups have used the CARS effectively as a measure of autism symptom severity in subjects with FXS (Bailey et al., 2001; Demark et al., 2003; Hatton et al., 2009; Levitas et al., 1983). Because the participants participated in the Carolina Fragile X Project, a longitudinal study, many had been administered the CARS on multiple occasions. For this analysis, CARS scores were averaged to yield a single score for each participant. Each subject had been assessed with the CARS between one and eight times $(M=3.5 ; S D=1.5)$, with scores ranging from 17.5 to $50.5(\mathrm{n}=209 ; M=27.2 ; S D=5.7)$. Other research groups have also used average CARS scores for the purpose of statistical analysis (Stone \& Caro-Martinez, 1990). Analysis

Variables. Analysis involved determining how well specific questionnaire items, based on previous research, may potentially distinguish the subgroup of children with FXS who have autism by predicting autism symptom severity as measured by the CARS. These selected questionnaire items (the independent variables) come from three major categories: items relating to social anxiety, withdrawal, and avoidance; items relating to play (specifically imagination, peer interaction, and object play); and items relating to adaptive socialization (specifically recognizing emotions in self and others). Candidate items that fall into these three categories are summarized in Tables 1, 2, and 3. It should be noted that considerable heterogeneity exists within the category of play (see Table 2). Items in this category relate to repetitive behaviors and restricted interests, such as object play, as well as social impairment, such as impaired peer interaction.

Statistical analysis. Exploratory analysis identified how well each of the candidate items (independent variables) correlated with the CARS total score (the dependent variable). Bivariate correlations with $p$-values less than .05 were considered statistically significant. A correlation matrix was generated for all variables to examine how the independent variables correlated with each other and with the dependent variable. Next, the group of independent variables identified in 
Table 1 was entered into a regression model with the CARS total score as the dependent variable. Items with significant unique contributions were identified using backward regression. Items with $p$-values greater than .10 were eliminated from the model. This process was repeated for the independent variables in Table 2, and then again for those in Table 3, resulting in three groups of variables from each of the three respective categories.

These three groups of variables were entered into a regression model, and backward regression was used to find the combination of predictor items that best explains the variance of the dependent variable (the CARS scores). Again, items with $p$-values greater than .10 were eliminated from the model. An $R^{2}$ statistic was generated that represents the percentage of variance explained by this optimal combination of predictor variables.

Then regression models were generated for each of the screening questionnaires (the SCQ and SRS), with the total screener score the sole predictor, and the CARS total score the dependent variable. An $R^{2}$ statistic was generated for each regression equation, representing how well each screener's total score predicts the variance in the CARS. Then the prediction ability of the selected combination of candidate items was compared to the prediction abilities of the SCQ and SRS total screener scores, as the goal is for a specialized screener to outperform existing screening instruments. After all regression analyses were completed, a factor analysis was used to examine the optimal combination of predictor variables identified in the final backward regression model. 
Table 1

Items that Relate to Social Anxiety ${ }^{1}$, Withdrawal ${ }^{2}$, and Avoidance $e^{2,3,4}$

\begin{tabular}{|c|c|}
\hline $\begin{array}{l}\text { Test/Item } \\
\text { Number }\end{array}$ & Item \\
\hline SRS1 & Seems much more fidgety in social situations than when alone \\
\hline$\underline{\mathrm{SRS} 3}$ & Seems self-confident when interacting with others \\
\hline SRS6 & Would rather be alone than with others \\
\hline SRS16 & Avoids eye contact or has unusual eye contact \\
\hline SRS23 & Does not join group activities unless told to do so \\
\hline SRS27 & Avoids starting social interactions with peers or adults \\
\hline SRS34 & Avoids people who want to be emotionally close to him or her \\
\hline$\underline{\mathrm{SRS} 45}$ & Focuses his or her attention to where others are looking or listening \\
\hline SRS64 & Is too tense in social settings \\
\hline SCQ19 & Does she/he have any particular friends or best friend? \\
\hline$\underline{\text { SCQ20 }}$ & $\begin{array}{l}\text { When she/he was } 4 \text { to } 5 \text {, did she/he ever talk with you just to be friendly (rather } \\
\text { than to get something)? }\end{array}$ \\
\hline$\underline{\mathrm{SCQ} 26}$ & $\begin{array}{l}\text { When she/he was } 4 \text { or } 5 \text {, did she/he usually look at you directly in the face when } \\
\text { doing things with you or talking with you? }\end{array}$ \\
\hline$\underline{\mathrm{SCQ} 28}$ & $\begin{array}{l}\text { When she/he was } 4 \text { to } 5 \text {, did she/he ever show you things that interested her/him } \\
\text { to engage your attention? }\end{array}$ \\
\hline$\underline{\mathrm{SCQ} 36}$ & $\begin{array}{l}\text { When she/he was } 4 \text { to } 5 \text {, did she/he seem interested in other children of } \\
\text { approximately the same age whom she/he did not know? }\end{array}$ \\
\hline$\underline{\mathrm{SCQ} 37}$ & $\begin{array}{l}\text { When she/he was } 4 \text { to } 5 \text {, did she/he respond positively when another child } \\
\text { approached him/her? }\end{array}$ \\
\hline
\end{tabular}

Note: Underlined items have been reverse scaled so that higher scores indicate greater autism symptom severity.

${ }^{1}$ Roberts et al., 2001; ${ }^{2}$ Budimirovic et al., 2006; ${ }^{3}$ Kau et al., 2004; ${ }^{4}$ Kaufman et al., 2004 
Table 2

Items Relating to Play ${ }^{1,2}$ (Specifically Imagination ${ }^{1}$, Peer Interaction ${ }^{1}$, and Object Play ${ }^{2}$ )

\begin{tabular}{ll}
$\begin{array}{c}\text { Test/Item } \\
\text { Number }\end{array}$ & \multicolumn{1}{c}{ Item } \\
SRS20 & Shows unusual sensory interests or strange ways of playing with toys \\
$\underline{\text { SRS22 }}$ & $\begin{array}{l}\text { Plays appropriately with children his or her own age } \\
\underline{\text { SRS40 }}\end{array} \quad \begin{array}{l}\text { Is imaginative, good at pretending } \\
\text { SCQ12 }\end{array} \quad \begin{array}{l}\text { Has she/he ever seemed more interested in parts of a toy or an object (e.g., } \\
\text { spinning the wheels of a car), rather than using the object as it was intended? }\end{array}$ \\
$\underline{\text { SCQ29 }} \quad \begin{array}{l}\text { When she/he was } 4 \text { to 5, did she/he ever offer to share things other than food with } \\
\text { you? }\end{array}$
\end{tabular}

When she/he was 4 to 5, did she/he ever spontaneously join in and try to copy the

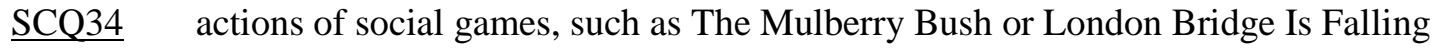
Down?

SCQ35 When she/he was 4 to 5, did she/he play pretend or make-believe games?

SCQ39 When she/he was 4 to 5 , did she/he ever play imaginative games with another child in a way that you could tell that they each understood what the other was doing?

SCQ40 When she/he was 4 to 5 , did she/he play cooperatively in games that required joining in with a group of other children such as hide-and-seek or ball games?

RBS5 Object usage (spins or twirls objects, twiddles or slaps or throws objects, lets objects fall out of hands)

RBS42 Preoccupation with part(s) of object rather than the whole object

RBS43 Fascination, preoccupation with movement/things that move (e.g., fans, clocks)

Note: Underlined items have been reverse scaled so that higher scores indicate greater autism symptom severity.

${ }^{1}$ Kaufman et al., 2004; ${ }^{2}$ Baranek et al., 2005 
Table 3

Items Relating to Adaptive Socialization ${ }^{1,2,3}$ (Specifically Recognizing Emotions in Self and Others ${ }^{3}$ )

Test/Item
Number

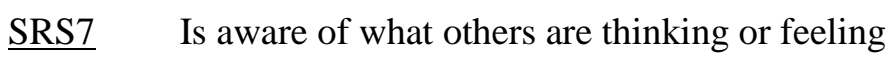

SRS12 Is able to communicate his or her feelings to others

SRS15 Is able to understand the meaning of other people's tone of voice and facial

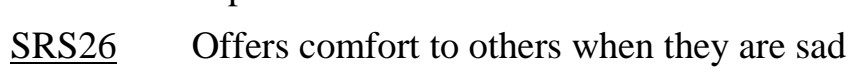

SRS38 Responds appropriately to mood changes in others

SRS60 Is emotionally distant, doesn't show his or her feelings

SCQ27 When she/he was 4 to 5 , did she/he smile back if someone smiled at him/her?

SCQ31 When she/he was 4 to 5 , did she/he ever try to comfort you when you were sad or hurt?

Note: Underlined items have been reverse scaled so that higher scores indicate greater autism symptom severity.

${ }^{1}$ Budimirovic et al., 2006; ${ }^{2}$ Kau et al., 2004; ${ }^{3}$ Kaufmann et al., 2004 


\section{Chapter 4: Results}

The analysis answered two primary research questions. First, do questionnaire items related to each of the three identified categories predict autistic behavior in children with FXS? This question was addressed in the first phase of analysis. Second, does an optimal combination of items from the three categories outperform traditional autism screeners in a sample of children with FXS? This question was addressed in the second phase of analysis.

\section{Phase I: Regression Analysis within Categories}

First, items were analyzed that relate to social anxiety, withdrawal, and avoidance (see Table 1). Of the candidate items, over half $(53 \%)$ had significant $(p<.05)$ bivariate correlations with CARS scores (see Table 11 in Appendix A). Three items with mild, non-significant negative correlations with CARS scores (most likely due to error) were eliminated from further analysis, as they could potentially confound the backward regression analysis. Using backward regression, an optimal combination of predictors was identified (see Table 4). This combination of three items was moderately predictive of CARS scores $\left(R^{2}=.44\right)$.

Table 4

Items Identified in Phase I Backward Regression from Table 1 that Relate to Social Anxiety, Withdrawal, and Avoidance

\begin{tabular}{cl}
\hline Item & \multicolumn{1}{c}{ Description } \\
\hline SRS23 & Does not join group activities unless told to do so \\
$\underline{\text { SRS45 }}$ & Focuses his or her attention to where others are looking or listening \\
SCQ 19 & Does she/he have any particular friends or best friend? \\
\hline Note: $\underline{\text { Underlined items have been reverse scaled so that higher scores indicate greater autism symptom severity. }}$
\end{tabular}


Next, items were analyzed that relate to play (see Table 2). Of the candidate items, the majority $(92 \%)$ had significant $(p<.05)$ bivariate correlations with CARS. In fact, most correlations $(75 \%)$ were highly significant $(p<.01)$. Two individual items from this category had markedly higher correlations with CARS scores than any other questionnaire items in this analysis. SRS20 and RBS5, which both relate to object play, had Pearson correlation coefficients of .57 and .56, respectively (see Table 12 in Appendix A). Using backward regression, an optimal combination of predictors was identified (see Table 5). This combination of three items was moderately predictive of CARS scores $\left(R^{2}=.48\right)$.

Table 5

Items Identified in Phase I Backward Regression from Table 2 that Relate to Play

\begin{tabular}{cl}
\hline Item & \multicolumn{1}{c}{ Description } \\
\hline SCQ34 & $\begin{array}{l}\text { When she/he was } 4 \text { to 5, did she/he ever spontaneously join in and try to copy the } \\
\text { actions of social games, such as The Mulberry Bush or London Bridge Is Falling } \\
\text { Down? }\end{array}$ \\
RBS5 & $\begin{array}{l}\text { Object usage (spins or twirls objects, twiddles or slaps or throws objects, lets objects } \\
\text { fall out of hands) }\end{array}$ \\
SRS20 & Shows unusual sensory interests or strange ways of playing with toy \\
\hline
\end{tabular}

Note: Underlined items have been reverse scaled so that higher scores indicate greater autism symptom severity.

Finally, items were analyzed that relate to adaptive socialization (see Table 3). Of the candidate items, most $(63 \%)$ had significant $(p<.05)$ bivariate correlations with CARS scores (see Table 13 in Appendix A). Using backward regression, an optimal combination of predictors was identified (see Table 6). This combination of two items was moderately predictive of CARS scores $\left(R^{2}=.28\right)$. 
Table 6

Items Identified in Phase I Backward Regression from Table 3 that Relate to Adaptive Socialization

\begin{tabular}{cl}
\hline Item & \multicolumn{1}{c}{ Description } \\
\hline$\underline{\text { SRS12 }}$ & Is able to communicate his or her feeling to others \\
$\underline{\text { SRS26 }}$ & Offers comfort to others when they are sad \\
\hline Note: $\underline{\text { Underlined items have been reverse scaled so that higher scores indicate greater autism symptom severity. }}$
\end{tabular}

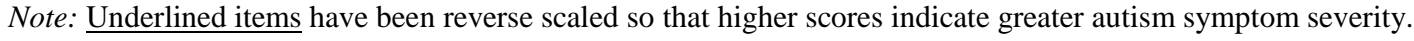

Phase II: Regression Analysis among Categories

The eight items identified from the three categories (summarized in Tables 4, 5, and 6) were all entered into a backward regression model with CARS scores as the dependent variable. Four items were identified as an optimal combination of predictors (see Table 7). The statistics generated in the Phase II backward regression are summarized in Appendix B. All three categories of items were represented. This combination of variables was highly predictive of CARS scores $\left(R^{2}=.59\right)$, outperforming traditional autism screeners for this sample of children with FXS (see Table 9).

Table 7

Items Identified in Phase II Backward Regression Analysis

\begin{tabular}{clc}
\hline Item & \multicolumn{1}{c}{ Description } & Category \\
\hline SRS23 & Does not join group activities unless told to do so & $\begin{array}{c}\text { Table 1: Social anxiety, } \\
\text { withdrawal, and } \\
\text { avoidance }\end{array}$ \\
$\underline{\text { SRS45 }}$ & $\begin{array}{l}\text { Focuses his or her attention to where others are looking } \\
\text { or listening }\end{array}$ & $\begin{array}{c}\text { Table 1: Social anxiety, } \\
\text { withdrawal, and } \\
\text { avoidance }\end{array}$ \\
RBS5 & $\begin{array}{l}\text { Object usage (spins or twirls objects, twiddles or slaps or } \\
\text { throws objects, lets objects fall out of hands) }\end{array}$ & Table 2: Play \\
$\underline{\text { SRS26 }}$ & Offers comfort to others when they are sad & $\begin{array}{c}\text { Table 3: Adaptive } \\
\text { Socialization }\end{array}$ \\
\hline
\end{tabular}

Note: Underlined items have been reverse scaled so that higher scores indicate greater autism symptom severity. 


\section{Factor Analysis}

After all regression analyses were completed, a factor analysis was used to examine the optimal combination of predictor variables identified in the final backward regression model. However, due to the small sample size $(N=60)$ and the high intercorrelations of the predictor variables identified in the final backward regression model (see Table 8), the factor analysis did not yield useful results. All items loaded onto a single factor.

Table 8

Intercorrelations Between Items Identified in Phase II Analysis

\begin{tabular}{|c|c|c|c|c|}
\hline Item & SRS23 & $\underline{\text { SRS45 }}$ & RBS5 & $\underline{\text { SRS26 }}$ \\
\hline SRS23 & - & .104 & .252 & .145 \\
\hline SRS45 & & - & $.352^{* *}$ & .205 \\
\hline RBS5 & & & - & $.443^{* *}$ \\
\hline SRS26 & & & . & - \\
\hline
\end{tabular}

Table 9

Prediction of CARS Scores

\begin{tabular}{lc}
\hline \multicolumn{1}{c}{ Predictor } & $R^{2}$ \\
\hline SCQ Total Score & .24 \\
SRS Total Score & .27 \\
Identified Items & .59 \\
(SRS23, $\underline{\text { SRS45 }}, \mathrm{RBS5}, \underline{\text { SRS26) }})$ & \\
\hline $\begin{array}{l}\text { Note: } \text { Underlined items have been reverse } \\
\text { scaled so that higher scores indicate greater } \\
\text { autism symptom severity. }\end{array}$
\end{tabular}

\section{Sensitivity and Specificity}

When the analysis was originally planned, computing composite scores and analyzing sensitivity and specificity were not included, as differences in scaling between the SCQ (2-point yes/no scale) and the SRS and RBS (5-points Likert scales) posed methodological problems. However, the final backward regression analysis resulted in items from only the SRS and RBS questionnaires, eliminating the problem with scaling. Items on both of these tests are scaled similarly on a Likert scale and coded into values of $0,1,2,3$, or 4 . Because of the equivalent scaling, it is reasonable to sum the scores from these items (summarized in Table 7) to compute a composite score for the identified items. Composite scores could range from 0 to 16. 
Composite scores were calculated for all subjects. Then, subjects were classified into two groups (Autism and No Autism) based on CARS scores. Subjects with CARS scores of 30 or greater were classified into the 'Autism' group, while subjects with CARS scores less than 30 were classified into the 'No Autism' group. This resulted in 17 subjects (28\%) in the 'Autism' group, and 43 subjects (72\%) in the 'No Autism' group. The proportion of boys classified into the 'Autism' group (28\%) is consistent with other estimates of autism prevalence in boys with FXS (Clifford et al., 2007; Hagerman et al., 2006; Hatton et al., 2006; Lewis et al., 2006; Rogers et al., 2001).

Then, the composite scores were analyzed as predictors of autism classification. Different cut-off scores were considered by calculating how many subjects would be correctly sorted into each group (Autism or No Autism) as a function of the cut-off score (see Table 10). The optimal cut-off score, 6 , is both highly sensitive (83\%) and specific (79\%).

Table 10

Sensitivity and Specificity of Summed Score of Identified Items $(N=60)$

\begin{tabular}{ccccc}
\hline Cut-off & $\begin{array}{c}\text { Subjects Correctly } \\
\text { Identified in } \\
\text { 'Autism' Group }\end{array}$ & $\begin{array}{c}\text { Subjects Correctly } \\
\text { Identified in } \\
\text { 'No Autism' Group }\end{array}$ & Sensitivity & Specificity \\
\hline 11 & 1 & 43 & $6 \%$ & $100 \%$ \\
10 & 5 & 43 & $29 \%$ & $100 \%$ \\
9 & 6 & 43 & $35 \%$ & $100 \%$ \\
8 & 9 & 40 & $53 \%$ & $93 \%$ \\
7 & 11 & 38 & $65 \%$ & $88 \%$ \\
$\mathbf{6}^{*}$ & $\mathbf{1 4}$ & $\mathbf{3 4}$ & $\mathbf{8 2 \%}$ & $\mathbf{7 9 \%}$ \\
5 & 17 & 24 & $100 \%$ & $56 \%$ \\
\hline
\end{tabular}

*optimal cut-off score 


\section{Chapter 5: Discussion}

\section{Phase I Analysis}

As hypothesized, questionnaire items related to each of the three identified categories (social anxiety, withdrawal, and avoidance; play; adaptive socialization) were highly predictive of autistic behavior in children with FXS. This was anticipated, as these categories of items were constructed based on findings in previous research (Baranek et al., 2005; Budimirovic et al., 2006; Kau et al., 2004; Kaufman et al, 2004; Roberts et al., 2001). However, the individual items that emerged as the best single predictors of autism severity were somewhat surprising.

While many researchers suggest that social behaviors best distinguish children with comorbid autism and FXS from other children with FXS (Budimirovic et al., 2006; Kau et al., 2004; Kaufman et al, 2004; Roberts et al., 2001), in this study, play items relating to restricted interests and repetitive behaviors emerged as the best single predictors of autism symptom severity. Two items relating to unusual and repetitive object play (SRS20 and RBS5) each had markedly higher bivariate correlations with CARS scores than any other items. Although one research group (Baranek et al., 2005) found that early object play may differentiate infants with FXS from infants with other developmental disabilities, their analysis did not include subgroups of FXS subjects with and without autism. A thorough literature review did not reveal any research that used substantive quantitative data to suggest that object play, or any other specific repetitive behavior, may distinguish children with comorbid FXS and autism from other children with FXS. This may be the first study to support specific repetitive behaviors as a key determinant of autism in FXS. 
While items relating to repetitive behavior were surprisingly powerful predictors, a number of items relating to social behaviors were surprisingly poor predictors of autistic behavior. For example, almost half (47\%) of items relating to social anxiety, withdrawal, and avoidance did not have significant $(p=.05)$ bivariate correlations with CARS scores (see Table 11 in Appendix A). The two poorest single predictors (SRS16 and SCQ26) were the only two selected items that target eye contact as a determinant of autism. While this may seem to contradict previous research that suggests eye contact may be closely tied to autism in FXS (Roberts et al., 2001), this is not the case. Roberts and colleagues used laboratory observation data to support modulated eye contact as a correlate of autism status. In their research, all FXS subjects tended to show similarly poor initial eye contact with a novel examiner, but subjects without autism demonstrated improved eye contact after being exposed to the examiner over time, while subjects with autism did not demonstrate marked improvement. In contrast, the present study uses data collected via parent report. These parent report ratings captured a general impression of eye contact, which was poor among most subjects regardless of autism status. Therefore, these two studies do not contradict each other, but instead suggest that although modulated eye contact may be a determinant of autism status in a structured laboratory setting with multiple observations, this prediction ability is simply not captured in a parent-report questionnaire.

Other poor predictor items were somewhat qualitatively similar as they tended to be more subjective and less directly observable than other items tapping a similar behavior. For example, item $\underline{\text { SRS15 }}$ (is able to understand the meaning of other people's tone of voice and facial expressions) was a poor single predictor, as it is rather subjective and requires the parent to infer what the child does or does not understand. However, SRS26 (offers comfort to others when they are $s a d$ ) proved to be a more powerful predictor as it is more objective and directly observable. Consequently, a screening instrument for autism in the FXS population should probably focus on 
specific, observable behaviors rather than general statements that require parent respondents to make subjective judgments.

\section{Phase II Analysis}

The second phase of analysis confirmed the hypothesis that an optimal combination of items from the three categories would outperform traditional autism screeners in this sample of children with FXS (see Table 9). As summarized in Table 7, the final backward regression analysis yielded a combination of four items that optimally predict CARS scores. Notably, each of the three categories devised in the hypothesis (social anxiety, withdrawal, and avoidance; play; adaptive socialization) were represented.

Three major implications can be drawn from this combination of four items. First, these items are four of the most observable and objective, reiterating the need to focus on clear, observable behaviors when creating parent-report questionnaires. Second, the four items represent two of the three major impairments that define autism: social impairment and repetitive behavior. The item representing repetitive behavior (RBS5) is the strongest single predictor of the four items. This item focuses on stereotyped object play. The other three items ( $\underline{\operatorname{SRS} 26}, \underline{\mathrm{SRS} 45}$, and SRS23) target social impairments. Specific types of social impairment include lack of empathy (SRS26), lack of joint attention (SRS45), and social avoidance (SRS23). Finally, the four items are highly correlated with each other (see Table 8), suggesting that as children with FXS display increased repetitive behaviors (as observed in object play), they tend to display similarly elevated levels of social impairment. In other words, a pattern of interrelated behaviors distinguishes children who have comorbid autism and FXS from other children with only FXS.

Notably, the only significant $(p<.05)$ intercorrelations both involved the item representing stereotypical object play (RBS5). This item was significantly correlated with items describing lack of joint attention ( $\underline{\text { SRS45) }}$ ) and lack of empathy (SRS26). The association between object play and joint attention may stem from impairments in imitation skills. The imitation skills 
of children with FXS have been found to be impacted by autism symptom severity, and imitation skills have been associated with object play and joint attention (Rogers, Hepburn, Stackhouse, \& Wehner, 2003). However, not all studies have found significant differences in imitation ability between children with comorbid FXS and autism and children with only FXS (Macedoni-Luksic, Greiss-Hess, Gosar, Chitwood, \& Hagerman, 2006).

The association between object play and lack of empathy may stem from impairments in theory of mind. Impairments in theory of mind, or "the ability to impute mental states to oneself and to others" (Baron-Cohen, Leslie, \& Frith, 1985, p. 39), have been found to discriminate children with FXS who do and do not have autism, even after controlling for cognitive functioning (Lewis et al., 2006). Clearly, empathy, which requires understanding and reacting to someone else's mental state, is closely tied to theory of mind. Theory of mind may be indirectly tied to unusual object play; children without theory of mind are understimulated by social stimuli, and may compensate by engaging in self-stimulating repetitive play.

\section{Sensitivity and Specificity}

The items identified through backward regression were selected because in combination they optimally predict CARS scores. While the statistic from the final regression analysis $\left(R^{2}=\right.$ .59) describes how well the four predictor items explain CARS scores, it does not describe how well these four predictors would correctly flag children with FXS who meet criteria for autism. An exploratory analysis compared the summed total of the four identified items to autism diagnosis as measured by the CARS. For the purpose of this analysis, subjects with CARS scores of 30 or greater were classified as having autism. Notably, when an optimal cut-off score is selected, these four items function as a screener with high sensitivity (82\%) and specificity (79\%, as shown in Table 9). While this analysis would be most telling in a replication study with a different sample of children with FXS, it does suggest that the items identified in the regression analysis may be useful as part of a screening tool. 


\section{Limitations and Directions for Future Research}

Several limitations should be considered before generalizing the findings of this study. First, candidate questionnaire items were chosen based on discriminating factors identified in the literature. Ideally, a factor analysis of all the questionnaire items would have been conducted to aid in this process, but the relatively small sample size $(N=60)$ did not permit this type of analysis. Next, when exploring sensitivity and specificity, CARS scores of 30 or greater were used to assign autism status, rather than a confirmed formal diagnosis in an educational setting or from a physician. In addition, the CARS is not considered a gold standard tool for diagnosing autism; it is better established as a continuous measure of autism symptom severity (Bailey et al., 2001; Hatton et al., 2009). Also, while the combination of identified questionnaire items is highly predictive of both autism status and symptom severity in this particular sample of 60 boys with FXS, these findings should be replicated with a different sample of children with FXS before being generalized to the entire FXS population.

\section{Conclusion}

There are several conclusions that can be drawn from this study. First, both social behavior and repetitive behaviors distinguish children with comorbid FXS and autism from other children with FXS. The results from this study suggest that repetitive behaviors related to stereotyped object play may be the best single predictor of autism in children with FXS. This has powerful implications for clinical settings; health care workers and early interventionists may be able to interview parents about a few key behaviors to gauge whether or not a young child with FXS should be formally evaluated for autism. Second, parent-report questionnaires should focus on objective questions that target observable behaviors. Finally, the results of this study provide evidence that a well designed parent-report questionnaire that focuses on specific distinguishing behaviors might serve as an effective tool for early identification of autism in boys with FXS. 


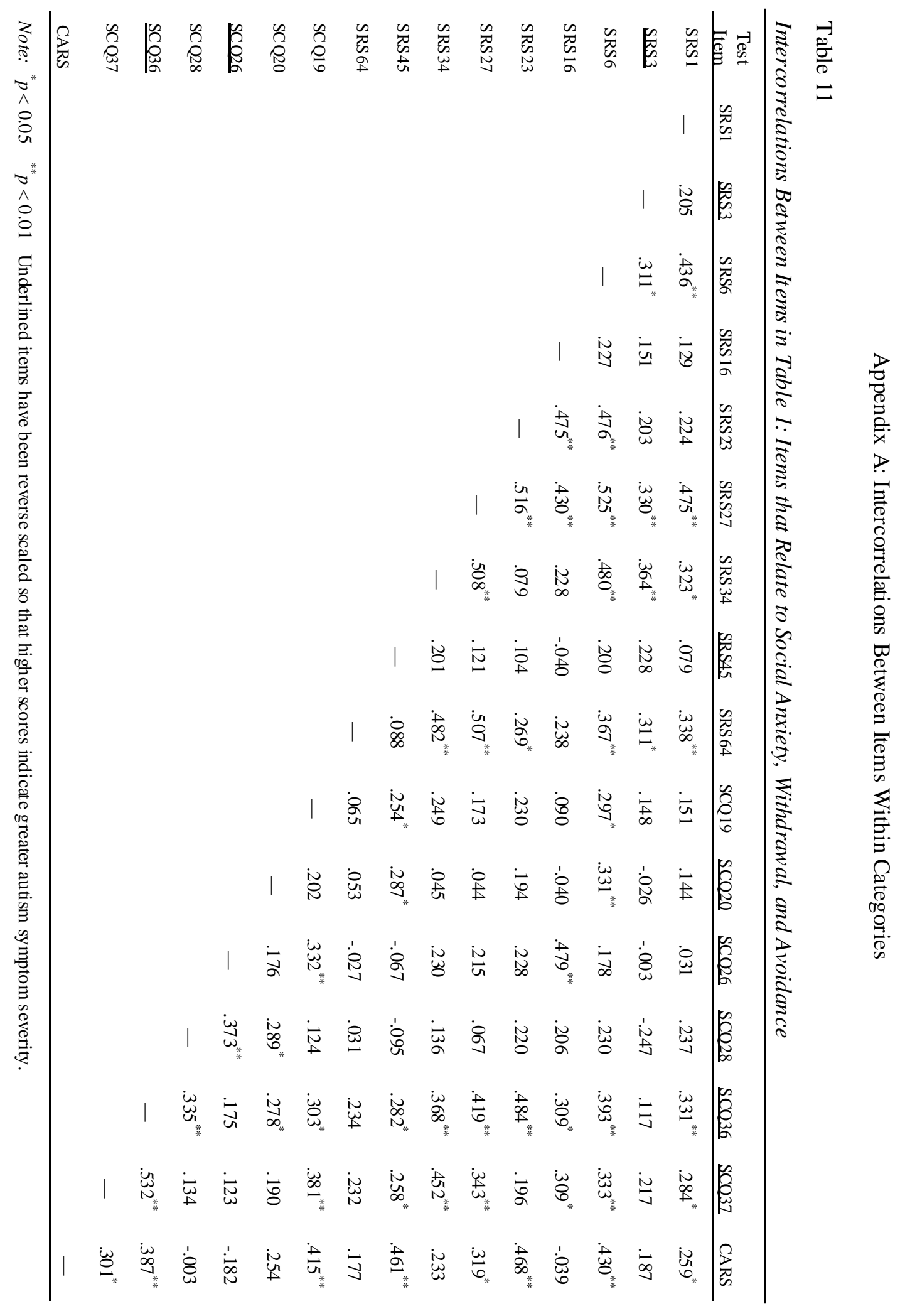




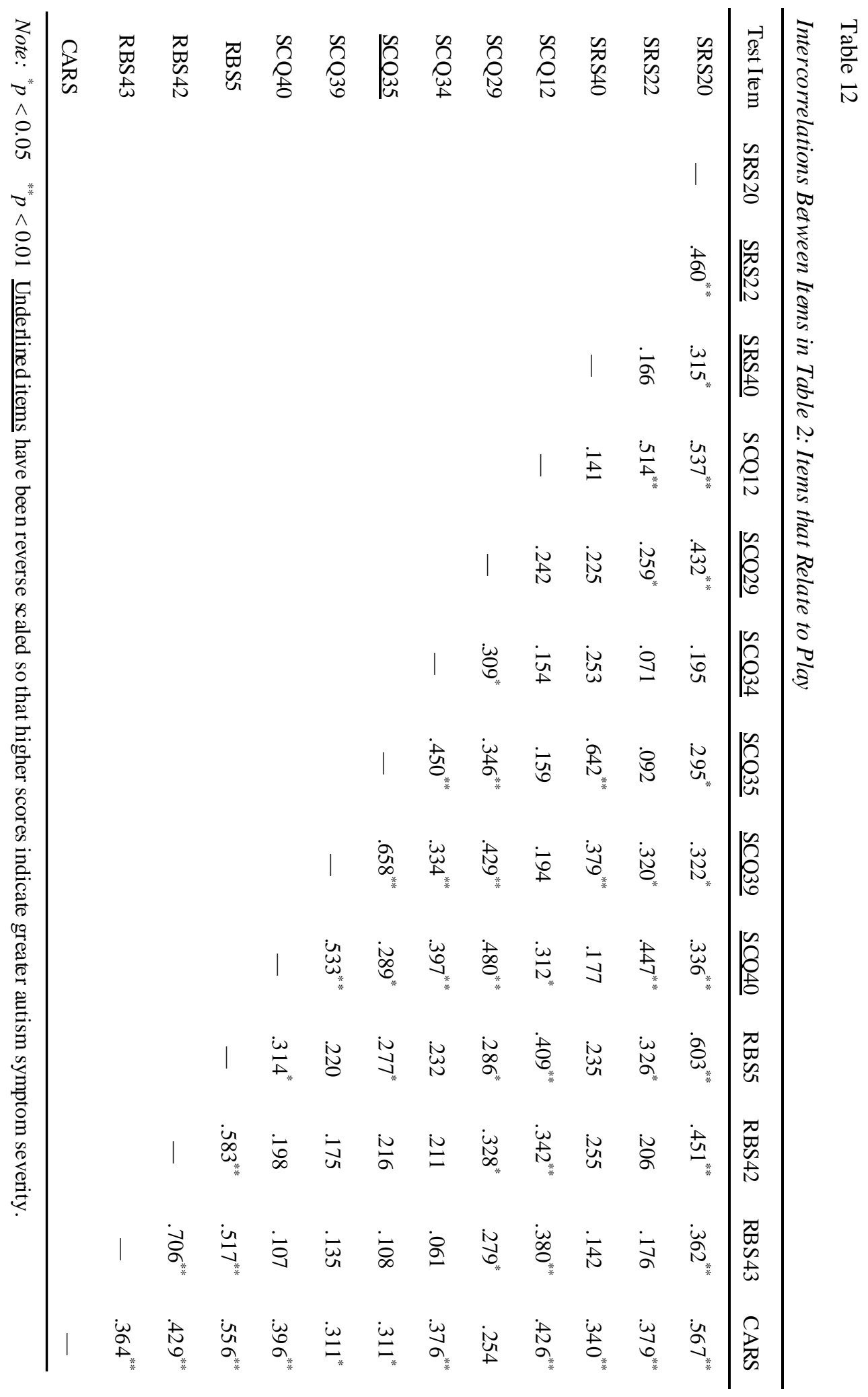




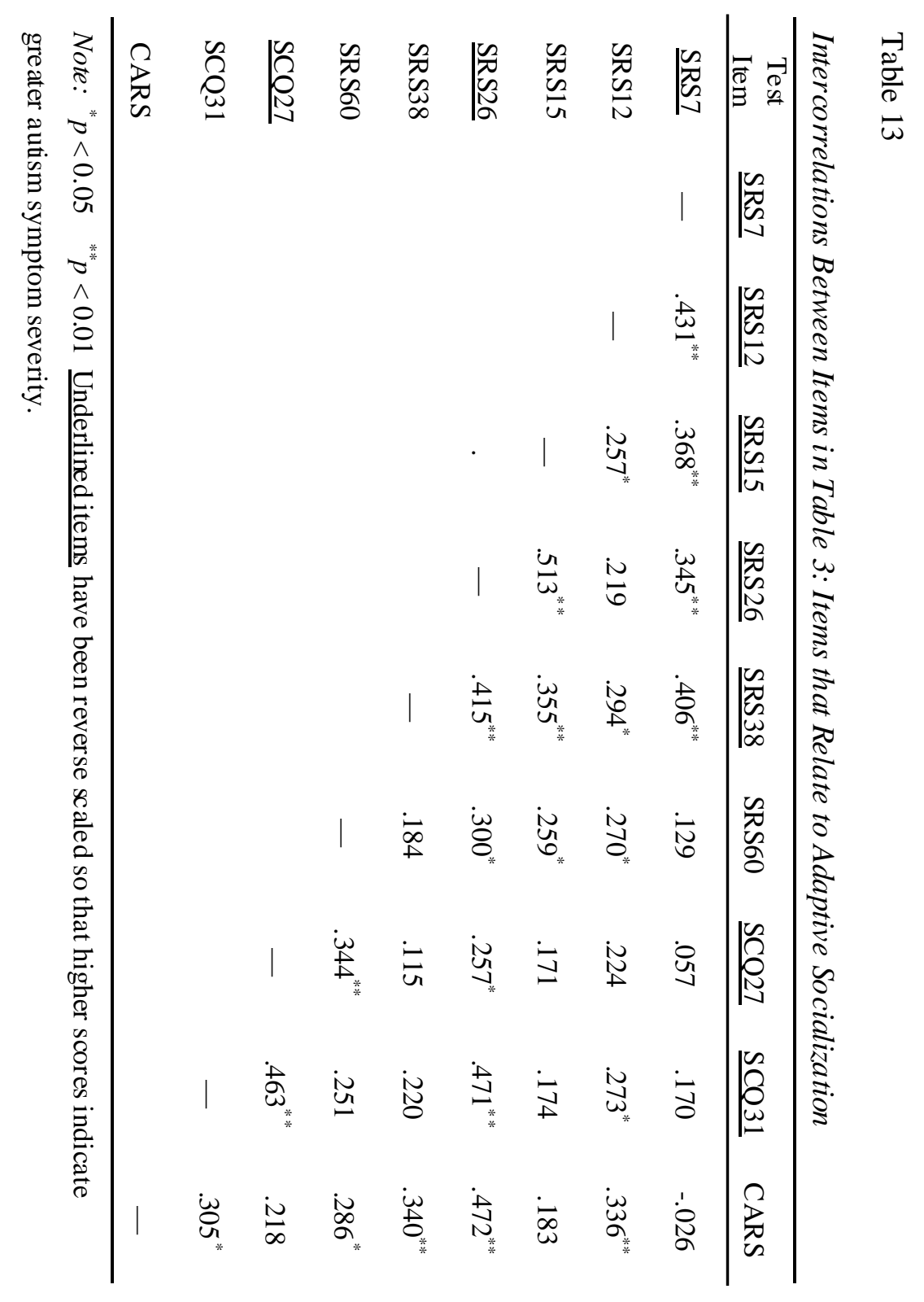


Appendix B: Phase II Backward Regression Statistics

Table 14

Phase II Backward Regression Statistics

\begin{tabular}{|c|c|c|c|c|c|c|}
\hline & Model & Item & $\beta$ & $S E$ & $t$ & $p$ \\
\hline \multirow[t]{8}{*}{1} & \multirow{8}{*}{$\begin{aligned} \text { CARS } \sim & \text { SRS23 }+\underline{\text { SRS } 45}+\text { SCQ19 }+ \text { SRS } 20 \\
& +\underline{\text { SRS } 34}+\text { RBS5 }+\underline{\text { SRS12 }}{ }^{*}+\underline{\text { SRS } 26}\end{aligned}$} & SRS23 & 1.308 & .489 & 2.677 & .010 \\
\hline & & $\underline{\text { SRS45 }}$ & 1.435 & .588 & 2.441 & .018 \\
\hline & & SCQ19 & 1.449 & .991 & 1.463 & .150 \\
\hline & & SRS20 & .744 & .559 & 1.332 & .189 \\
\hline & & $\underline{\text { SRS34 }}$ & -.433 & .566 & -.765 & .448 \\
\hline & & RBS5 & 1.260 & .685 & 1.838 & .072 \\
\hline & & $\underline{\text { SRS12* }}$ & -.114 & .648 & -.177 & .860 \\
\hline & & $\underline{\text { SRS26 }}$ & 1.466 & .525 & 2.795 & .007 \\
\hline \multirow[t]{7}{*}{2} & \multirow{7}{*}{$\begin{aligned} \text { CARS } \sim & \text { SRS } 23+\text { SRS45 }+ \text { SCQ19+SRS20 } \\
& +\underline{\text { SRS } 34^{*}+\operatorname{RBS} 5}+\underline{\text { SRS } 26}\end{aligned}$} & SRS23 & 1.293 & .476 & 2.714 & .009 \\
\hline & & $\underline{\text { SRS45 }}$ & 1.423 & .578 & 2.460 & .017 \\
\hline & & SCQ19 & 1.458 & .980 & 1.488 & .143 \\
\hline & & SRS20 & .729 & .547 & 1.334 & .188 \\
\hline & & ${\underline{S R S} 34^{*}}^{*}$ & -.459 & .542 & -.848 & .400 \\
\hline & & RBS5 & 1.251 & .677 & 1.848 & .070 \\
\hline & & $\underline{\text { SRS26 }}$ & 1.464 & .519 & 2.819 & .007 \\
\hline \multirow[t]{6}{*}{3} & \multirow{6}{*}{$\begin{aligned} \mathrm{CARS} \sim & \mathrm{SRS} 23+\underline{\mathrm{SRS} 45}+\mathrm{SCQ} 19+\mathrm{SRS} 20^{*} \\
& +\mathrm{RBS} 5+\underline{\mathrm{SRS} 26}\end{aligned}$} & SRS23 & 1.334 & .473 & 2.823 & .007 \\
\hline & & $\underline{\text { SRS45 }}$ & 1.422 & .577 & 2.465 & .017 \\
\hline & & SCQ19 & 1.345 & .968 & 1.389 & .171 \\
\hline & & SRS20* & .586 & .519 & 1.131 & .263 \\
\hline & & RBS5 & 1.288 & .674 & 1.911 & .062 \\
\hline & & $\underline{\text { SRS26 }}$ & 1.342 & .498 & 2.696 & .009 \\
\hline \multirow[t]{5}{*}{4} & \multirow{5}{*}{$\begin{aligned} \mathrm{CARS} \sim & \mathrm{SRS} 23+\underline{\mathrm{SRS} 45}+\mathrm{SCQ} 19^{*}+\mathrm{RBS} 5 \\
& +\underline{\mathrm{SRS} 26}\end{aligned}$} & SRS23 & 1.453 & .462 & 3.146 & .003 \\
\hline & & $\underline{\text { SRS45 }}$ & 1.542 & .569 & 2.713 & .009 \\
\hline & & SCQ19* & 1.536 & .956 & 1.606 & .114 \\
\hline & & RBS5 & 1.638 & .601 & 2.727 & .009 \\
\hline & & $\underline{\text { SRS26 }}$ & 1.364 & .499 & 2.734 & .008 \\
\hline \multirow[t]{4}{*}{5} & \multirow{4}{*}{$\mathrm{CARS} \sim \mathrm{SRS} 23+\underline{\mathrm{SRS} 45}+\mathrm{RBS} 5+\underline{\mathrm{SRS} 26}$} & SRS23 & 1.572 & .462 & 3.400 & .001 \\
\hline & & $\underline{\text { SRS45 }}$ & 1.717 & .566 & 3.033 & .004 \\
\hline & & RBS5 & 1.719 & .607 & 2.832 & .006 \\
\hline & & $\underline{\text { SRS26 }}$ & 1.455 & .503 & 2.895 & .005 \\
\hline
\end{tabular}

Note: underlined items have been reverse scaled so that higher scores indicate greater autism symptom severity *least significant predictor in model with $\mathrm{p}>.10$; removed from subsequent models 


\section{References}

Abrahams, B. S., \& Geschwind, D. H. (2008). Advances in autism genetics: On the threshold of a new neurobiology. Nature Reviews Genetics, 9, 493-493.

Achenbach T. M. \& Rescorla L. A. (2001). Manual for the ASEBA School-age Forms and Profiles. Burlington, VT: University of Vermont, Department of Psychiatry.

Aman, M., Singh, N., Stewart, A., \& Field, C. (1985). The aberrant behavior checklist: A behavior rating scale for the assessment of treatment effects. American Journal of Mental Deficiency, 89, 485-491.

Bailey A., Phillips W., \& Rutter M. (1996). Autism: Towards an integration of clinical, genetic, neuropsychological and neurobiological perspectives. Journal of Child Psychology and Psychiatry, 37, 89-126.

Bailey D. B., Hatton, D. D., Mesibov, G., Ament, N., \& Skinner, M. (2000). Early development, temperament, and functional impairment in autism and fragile $\mathrm{X}$ syndrome. Journal of Autism \& Developmental Disorders, 30, 49-60.

Bailey, D. B., Hatton, D. D., Skinner M., \& Mesibov, G. (2001). Autistic behavior, FMR1 protein, and developmental trajectories in young males with fragile $\mathrm{X}$ syndrome. Journal of Autism and Developmental Disorders, 31, 165-174.

Bailey, D. B., Roberts, J. E., Hooper, S. R., Hatton, D. D., Mirrett, P. L., Roberts, J. E., \& Schaaf, J. M. (2004). Research on fragile X syndrome and autism: Implications for the study of genes, environments, and developmental language disorders. In M.L. Rice \& S.F. Warren (Eds.), Developmental Language Disorders (pp. 121-152). Malwah, NJ: Lawrence Erlbaum Associates.

Baranek, G. T., Danko, C. D., Skinner, M. L., Bailey, D. B., Hatton, D. D., Roberts, J. E., \& Mirrett, P. L. (2005). Video analysis of sensory-motor features in infants with fragile X syndrome at 9-12 Months of Age. Journal of Autism \& Developmental Disorders, 35, 645-656.

Baron-Cohen, S., Allen, J., \& Gillberg, C. (1993). Can autism be detected at 18 months? The needle, the haystack, and the CHAT. Annual Progress in Child Psychiatry \& Child Development, 95-103.

Baron-Cohen, S., Leslie, A., \& Frith, U. (1985). Does the autistic child have a 'theory of mind'?. Cognition, 21, 37-46.

Belmonte, M. K., \& Bourgeron, T. (2006). Fragile X syndrome and autism at the intersection of genetic and neural networks. Nature Neuroscience, 9, 1221-1225.

Bodfish, J. W., Symons, F. W., \& Lewis, M. H. (1999). The Repetitive Behavior Scale. Western Carolina Center Research Reports.

Budimirovic, D. B., Bukelis, I., Cox, C., Gray, R. M., Tierney, E., \& Kaufmann W. E. (2006). Autism spectrum disorder in fragile $\mathrm{X}$ syndrome: Differential contribution of adaptive socialization and social withdrawal. American Journal of Medical Genetics Part A, 140A, 1814-1826. 
Catania. M. V., D’Antoni, S., Bonaccorso, C. M., Aronica, E., Bear, M. F., \& Nicoletti, F. (2007). Group I metabotropic glutamate receptors: A role in neurodevelopmental disorders? Molecular Neurobiology, 35, 298-307.

Charman, T., Baird, G., Simonoff, E., Loucas, T., Chandler, S., \& Meldrum, D. (2007). Efficacy of three screening instruments in the identification of autistic spectrum disorders. British Journal of Psychiatry, 191, 554-559.

Clifford, S., Dissanayake, C., Bui, Q. M., Huggins, R., Taylor, A. K., \& Loesch, D. Z. (2007). Autism spectrum phenotype in males and females with fragile $\mathrm{X}$ full mutation and premutation. Journal of Autism \& Developmental Disorders, 37, 738-747.

Cohen I. L., Vietze P. M., Sudhalter V., Jenkins E. C. \& Brown W. T. (1989). Parent-child dyadic gaze patterns in fragile $\mathrm{X}$ males and in non-fragile $\mathrm{X}$ males with autistic disorder. Journal of Child Psychology and Psychiatry, 30, 845-56.

Constantino, J. N. \& Gruber, C. P. (2005). Social Responsiveness Scale (SRS).Western Psychological Services.

Collacott, R. A., Cooper, S., \& McGrother, C. (1992). Differential rates of psychiatric disorders in adults with down's syndrome compared with other mentally handicapped adults. British Journal of Psychiatry, 161, 671-674.

Crawford, D. (2001). FMRI and Fragile X Syndrome. From http://www.cdc.gov/genomics/hugenet/file/print/factsheets/FS_FragileX.pdf

Demark, J., Feldman, M., \& Holden J. (2003). Behavioral relationship between autism and fragile X syndrome. American Journal of Mental Retardation, 108, 314-326.

Gillberg C., Persson E., \& Wahlstrom J. (1986). The autismfragile-X syndrome (AFRAX): a population-based study of ten boys. Journal of Mental Deficiency Research 30, 27-39.

Hagerman, R. J. (2002). Physical and behavioral phenotype. In R.J. Hagerman \& P.J. Hagerman, (Eds.), Fragile X Syndrome: Diagnosis, Treatment, and Research (3rd ed.). (pp. 3-87). Baltimore, MD: The John Hopkins University Press.

Hagerman, R. J. (2006). Lessons from fragile X regarding neurobiology, autism, and neurodegeneration. Journal of Developmental \& Behavioral Pediatrics, 27, 63-74.

Hagerman, R., Jackson, C., Amiri, K., Silverman, A., O'Connor, R., \& Sobesky, W. (1992). Girls with fragile X syndrome: Physical and neurocognitive status and outcome. Pediatrics, 89, 395.

Happé, F., Ronald, A., \& Plomin, R. (2006). Time to give up on a single explanation for autism. Nature Neuroscience, 9, 1218-1220.

Hatton, D. D. \& Bailey, D. B. (2001). Fragile X syndrome and autism. In E. Schopler, N. Yirmiya, C. Shulman, \& L. Marcus (Eds.) The Research Basis for Autism Intervention. (pp. 75-89) New York: Kluwer Academic/Plenum Publishers. 
Hatton, D. D., Hooper, S. R., Bailey, D. B., Skinner, M. L., Sullivan, K. M., \& Wheeler, A. (2002). Problem behavior in boys with fragile X syndrome. American Journal of Medical Genetics Part A, 108, 105-116.

Hatton, D. D., Sideris, J., Skinner, M., Mankowski, J., Bailey D. B., Roberts J., \& Mirrett, P. (2006). Autistic behavior in children with fragile X syndrome: Prevalence, stability, and the impact of FMRP. American Journal of Medical Genetics Part A, 140A, 1804-1813.

Hatton, D., Wheeler, A., Sideris, J., Sullivan, K., Reichardt, A., Roberts, J., \& Clark, R. (2009). Developmental trajectories of young girls with fragile X syndrome. American Journal on Intellectual and Developmental Disabilities, 114, 161-171.

Hessl D., Dyer-Friedman J., Glaser B., Wisbeck J., Barajas R. G., Taylor A., \& Reiss A. L. (2001). The influence of environmental and genetic factors on behavior problems and autistic symptoms in boys and girls with fragile X syndrome. Pediatrics, 108, 88-96.

Kau, A., Tierney, E., Bukelis, I., Stump, M. H., Kates, W. R., Trescher, W. H. \& Kaufmann. W. E. (2004). Social behavior profile in young males with fragile $\mathrm{X}$ syndrome: Characteristics and specificity. American Journal of Medical Genetics, 126A, 9-17.

Kaufmann, W. E., Cortell, R., Kau, A., Bukelis I., Tierney E., Gray R., Cox C., Capone G., \& Stanard, P. (2004). Autism spectrum disorder in fragile X syndrome: Communication, social interaction, and specific behaviors. American Journal of Medical Genetics Part A, 129A, 225-234.

Kent, L., Evans, J., Paul, M., \& Sharp, M. (1999). Comorbidity of autistic spectrum disorders in children with down syndrome. Developmental Medicine \& Child Neurology, 41, 153-158.

Lam, K., \& Aman, M. (2007). The repetitive behavior scale-revised: Independent validation in individuals with autism spectrum disorders. Journal of Autism \& Developmental Disorders, $37,855-866$.

Levitas, A., Hagerman, R., Braden, M., Rimland, B., McBogg, P., \& Matus, I. (1983). Autism and the fragile X syndrome. Journal of Development and Behavioral Pediatrics, 4, 151-158.

Lewis, P., Abbeduto, L., Murphy, M., Richmond, E., Giles, N., Bruno, L., \& Schroeder, S. (2006). Cognitive, language and social-cognitive skills of individuals with fragile $\mathrm{X}$ syndrome with and without autism. Journal of Intellectual Disability Research, 50, 532-545.

Loesch, D. Z., Bui, Q. M., Dissanayake, C., Clifford, S., Gould, E., Bulhak-Paterson, D., Tassone, F., Taylor, A. D., Hessl, D., Hagerman, R., \& Huggins, R. M. (2007). Molecular and cognitive predictors of the continuum of autistic behaviours in fragile X. Neuroscience and Biobehavioral Reviews, 31, 315-326.

Lord, C., Rutter, M., \& Le Coteur, A. (1994). Autism diagnostic interview-revised: A revised version of a diagnostic interview for caregivers of individuals with possible pervasive developmental disorders. Journal of Autism \& Developmental Disorders, 24, 659-685.

Macedoni-Luksic, M., Greiss-Hess, L., Gosar, D., Chitwood, K., \& Hagerman, R. (2006). On imitation in autism: Children with fragile $\mathrm{X}$ syndrome with and without autism. Developmental Medicine \& Child Neurology, 48, 35-36. 
Mancil, G. R., Conroy, M. A., Nakao, T., \& Alter, P. J. (2006). Functional communication training in the natural environment: A pilot investigation with a young child with autism spectrum disorder. Education and Treatment of Children, 29, 615-633.

Mullen, E. (1995). Mullen Scales of Early Learning (MSEL) manual. Circle Pines, NY: American Guidance Service.

National Research Council. (2001). Educating children with autism. Washington, DC: National Academy Press.

Philofsky A., Hepburn S. L., Hayes A., Hagerman R., Rogers, S. J. (2004). Linguistic and cognitive functioning and autism symptoms in young children with fragile $\mathrm{X}$ syndrome. American Journal of Mental Retardation, 109, 208-218.

Price, J., Roberts, J., Vandergrift, N., \& Martin, G. (2007). Language comprehension in boys with fragile X syndrome and boys with down syndrome. Journal of Intellectual Disability Research, $51,318-326$.

Roberts, J. E., Mirrett, P., Burchinal, M. (2001). Receptive and expressive communication development of young males with fragile X syndrome. American Journal of Mental Retardation, 106, 216-230.

Roberts, J., Weisenfeld, L., Hatton, D., Heath, M., \& Kaufmann, W. (2007). Social approach and autistic behavior in children with fragile X syndrome. Journal of Autism \& Developmental Disorders, 37, 1748-1760.

Rogers, S., Hepburn, S., Stackhouse, T., \& Wehner, E. (2003). Imitation performance in toddlers with autism and those with other developmental disorders. Journal of Child Psychology and Psychiatry, 44, 763-781.

Rogers S. J., Wehner, E., \& Hagerman, R. J. (2001). The behavioral phenotype in fragile X: Symptoms of autism in very young children with fragile $\mathrm{X}$ syndrome, idiopathic autism, and other developmental disorders. Journal of Developmental Behavioral Pediatrics, 22, 409-417.

Rutter, M., Bailey, A. \& Lord, C. (2003). Social Communication Questionnaire (SCQ).Western Psychological Services.

Scambler, D. J., Hepburn, S. L., Hagerman, R. J., \& Rogers, S. J. (2007). A preliminary study of screening for risk of autism in children with fragile $\mathrm{X}$ syndrome: Testing two risk cut-offs for the checklist for autism in toddlers. Journal of Intellectual Disability Research, 51, 269-276.

Schopler, E., Reichler, R.J., \& Renner, B.R. (1988). The Childhood Autism Rating Scale (CARS). Los Angeles: Western Psychological Services.

Stone, W., \& Caro-Martinez, L. (1990). Naturalistic observations of spontaneous communication in autistic children. Journal of Autism and Developmental Disorders, 20, 437-453.

Turk J. \& Graham P. (1997) Fragile X syndrome, autism and autistic features. Autism, 1, 105-127. 